Supporting Information

\title{
An Integrated Liquid Cooling System Based on Galinstan Liquid Metal Droplets
}

Jiu Yang Zhu, Shi-Yang Tang, Khashayar Khoshmanesh*, Kamran Ghorbani

School of Engineering, RMIT University, Melbourne, Victoria, 3001, Australia

* Corresponding author: Khashayar.khoshmanesh@rmit.edu.au 


\section{Supporting Information 1: Details of experimental setup}

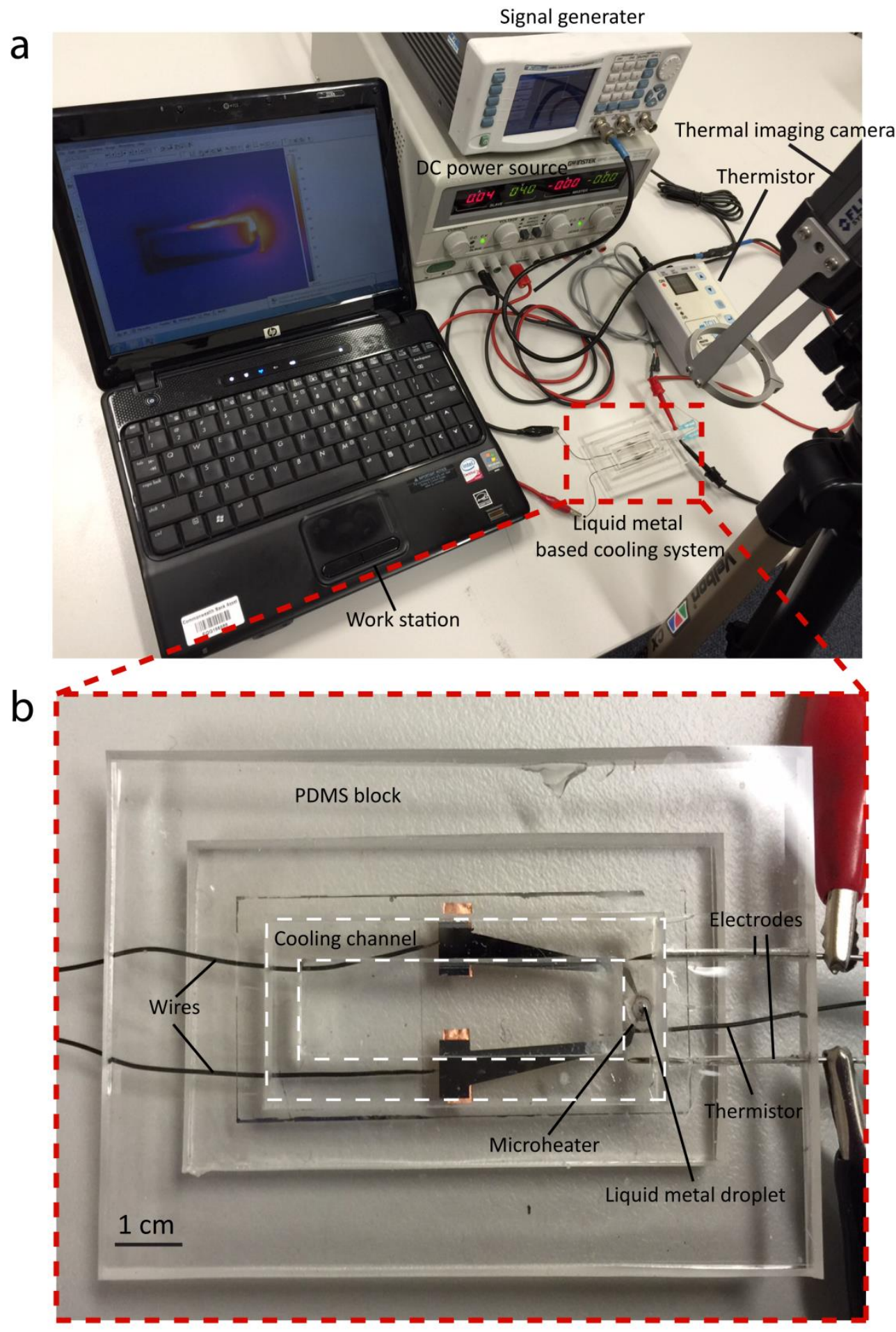

Figure S1: (a) Experimental setup. (b) Close-up image of the liquid metal based cooling system. 
Supporting Information 2: Measuring the flow rate of $\mathrm{NaOH}$ generated by liquid metal pump

In order to measure the flow rate of $\mathrm{NaOH}$ solution through the cooling channel, we add a droplet of blue food dye into the channel. Then, we actuate the droplet with a square wave DC signal with desired magnitude and frequency. We capture the induced flow of $\mathrm{NaOH}$ solution using a camera, and analyse the sequential snapshots to measure the amount of time it takes for the flow to circulate one cycle, as shown in Figure S2. The average velocity of flow is calculated by dividing the length of the cooling channel by the measured time. The flow rate is then calculated by multiplying the average velocity by the cross sectional area of the cooling channel.
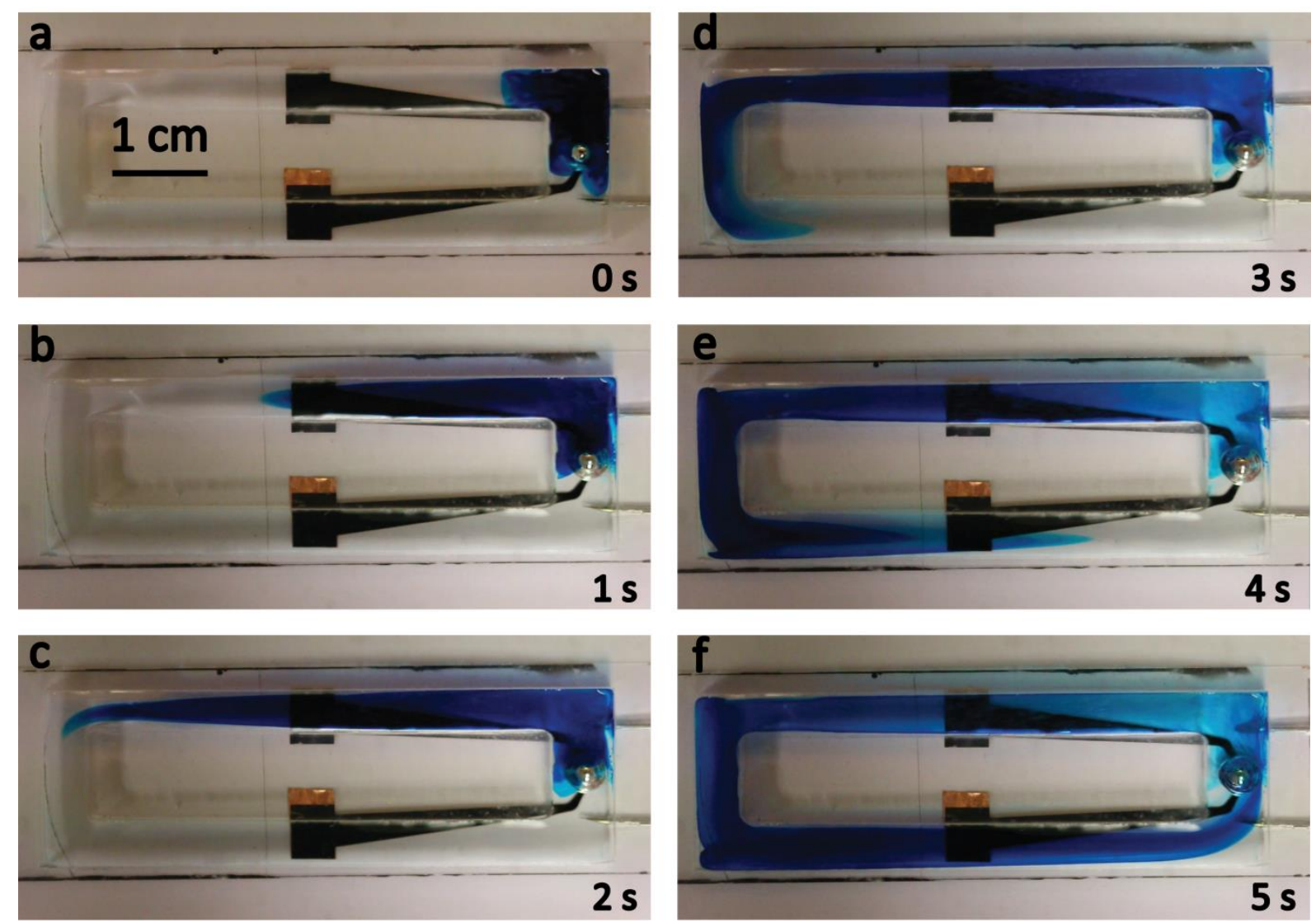

Figure S2: Actuation of liquid metal based pump with a droplet of dye used to visualize the induced flow. (a-f) Sequential snapshots of flow using a $3 \mathrm{~mm}$ Galinstan droplet immersed in $0.3 \mathrm{M} \mathrm{NaOH}$, when operated with a square wave signal $\left(200 \mathrm{~Hz}, 5 \mathrm{~V}_{\mathrm{p}-\mathrm{p}}, 2.5 \mathrm{~V}\right.$ DC offset and $50 \%$ duty cycle). 


\section{Supporting Information 3: Estimating the flow rate of $\mathrm{NaOH}$ with respect to}

\section{parameters of the cooling system}

The shear stress over the surface of liquid metal droplet can be approximated as below:

$$
\left.\frac{\partial \gamma}{\partial \vec{t}}\right|_{\text {Droplet }}=\tau_{\text {Droplet }} \rightarrow \tau_{\text {Droplet }} \sim \frac{\Delta \gamma_{\text {Droplet }}}{\pi 0.5 D_{\text {Droplet }}}
$$

For internal flows, the relation between the shear stress over the surfaces of the liquid metal droplet and the cooling channel walls can be described as below:

$$
\begin{aligned}
& \tau_{\text {Droplet }} \cdot \mathrm{A}_{\text {Droplet }}=\tau_{\text {Channel }} \cdot \mathrm{A}_{\text {Channel }} \\
& \rightarrow \tau_{\text {Channel }}=\tau_{\text {Droplet }} \cdot \frac{\pi D_{\text {Droplet }}^{2}}{L_{\text {Channel }} H_{\text {Channel }}}
\end{aligned}
$$

The shear stress over the surface of cooling channel walls can be approximated as below:

$$
\tau_{\text {Channel }}=\left.\mu_{\text {NaOH }} \frac{\partial U}{\partial n}\right|_{\text {Channel }} \sim \mu_{N a O H} \frac{U_{\text {NaOH }}}{H_{\text {Channel }}} \sim \mu_{N a O H} \cdot \frac{Q_{N a O H}}{W_{\text {Channel }} H_{\text {Channel }}^{2}}
$$

Therefore, the flow rate of $\mathrm{NaOH}$ through the cooling channel is obtained as below:

$$
Q_{\text {NaOH }} \sim \tau_{\text {Channel }} \frac{W_{\text {Channel }} H_{\text {Channel }}^{2}}{\mu_{\text {NaOH }}}
$$

Combining equations $\mathrm{S} 4, \mathrm{~S} 2$ and $\mathrm{S} 1$, the flow rate of $\mathrm{NaOH}$ is obtained as below:

$$
\begin{aligned}
Q_{\text {NaOH }} \sim \tau_{\text {Droplet }} \cdot \pi D_{\text {Droplet }}^{2} \cdot \frac{W_{\text {Channel }} H_{\text {Channel }}}{L_{\text {Channel }}} \cdot \frac{1}{\mu_{\text {NaOH }}} \\
\rightarrow Q_{N a O H} \sim \Delta \gamma_{\text {Droplet }} \cdot D_{\text {Droplet }} \cdot \frac{W_{\text {Channel }} H_{\text {Channel }}}{L_{\text {Channel }}} \cdot \frac{1}{\mu_{\text {NaOH }}}
\end{aligned}
$$

The surface tension gradient over the surface of liquid metal droplet is due to continuous electrowetting, created by applying a voltage difference over the two sides of liquid metal, which can be calculated as: $\Delta \gamma_{\text {Droplet }}=c V_{o} \Delta \varphi{ }^{1}$. As a result, the flow rate of $\mathrm{NaOH}$ with respect to the parameters of the system can be described as below:

$$
\begin{gathered}
Q_{\mathrm{NaOH}} \sim c V_{\mathrm{O}} \Delta \varphi \cdot D_{\text {Droplet }} \cdot \frac{W_{\text {Channel }} H_{\text {Channel }}}{L_{\text {Channel }}} \cdot \frac{1}{\mu_{\text {NaOH }}} \\
\rightarrow Q_{\mathrm{NaOH}} \sim c V_{\mathrm{O}} \cdot \frac{V_{\text {Electrode }}}{A_{\text {Gap }}} \cdot D_{\text {Droplet }}^{2} \cdot \frac{W_{\text {Channel }} H_{\text {Channel }}}{L_{\text {Channel }}} \cdot \frac{1}{\mu_{\mathrm{NaOH}}}
\end{gathered}
$$


Supporting Information 4: Variations of $\mathrm{NaOH}$ temperature within the cooling channel measured by infrared camera at different flow rates

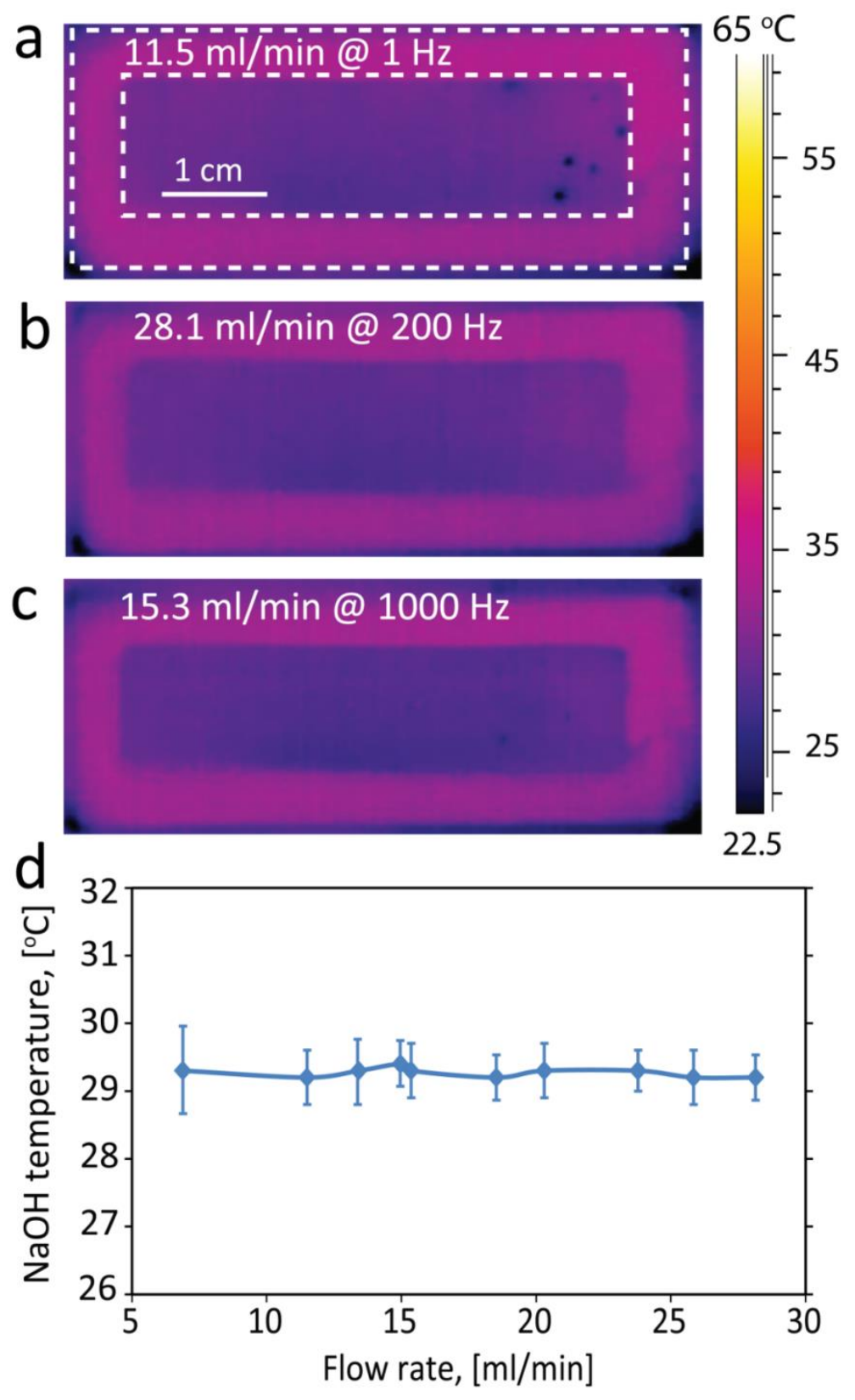

Figure S3: $\mathrm{NaOH}$ temperature within the left arm of cooling channel measured by infrared camera, when operated the droplet with a square wave signal ( $5 \mathrm{~V}_{\mathrm{p}-\mathrm{p}}, 2.5 \mathrm{~V}$ DC offset and $50 \%$ duty cycle) of different frequencies: (a) at $1 \mathrm{~Hz}$, (b) at $200 \mathrm{~Hz}$, (c) at $1000 \mathrm{~Hz}$. (d) $\mathrm{NaOH}$ temperature measured by infrared camera $v s$ droplet operating frequency. (e) $\mathrm{NaOH}$ temperature measured by infrared camera $v s$ flow rate. 
Supporting Information 5: Comparing the cooling performance of liquid metal droplet

(Case 2: in the absence of $\mathrm{NaOH}$ solution) under different diameters of droplet

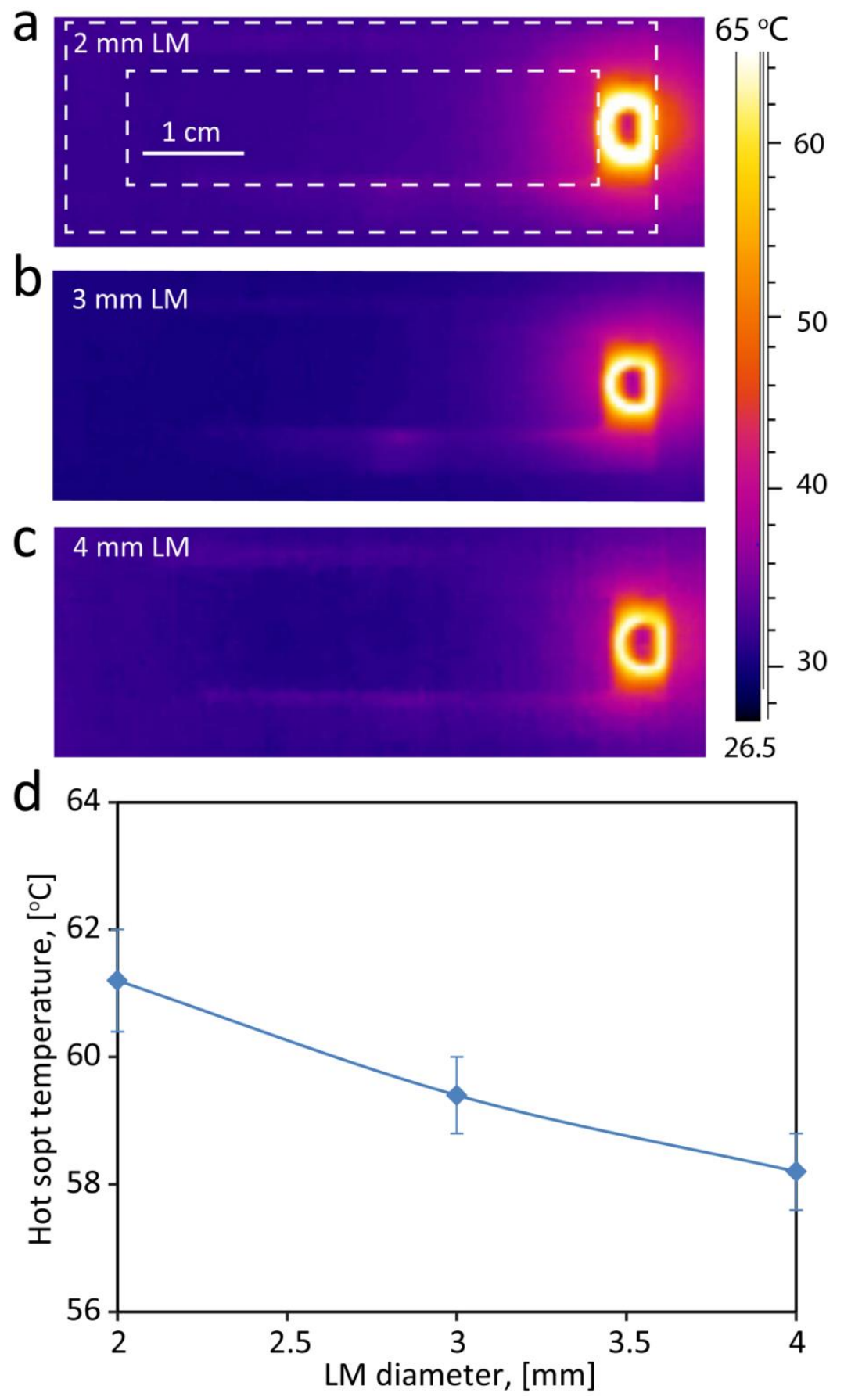

Figure S4: Hot spot temperature vs size of liquid metal droplet when the liquid metal droplet is not energized while energizing microheater with a $3.5 \mathrm{~V}, 0.04$ A DC signal: (a-c) Temperature contours measured by thermal imaging camera. (d) Hot spot temperatures obtained by thermistor $v s$ different sizes of Galinstan droplet. 
Placing a liquid metal droplet over the hot spot (in the absence of $\mathrm{NaOH}$ solution) leads to natural convection of air over the surface of droplet, and thus the temperature difference between the hot spot and the surrounding air can be calculated as below:

$$
T_{\text {Hot spot }}-T_{\text {Air }}=q\left(\left.\frac{L_{g}}{k_{g} A_{g}}\right|_{\text {Glass }}+\left.\frac{L_{c}}{k_{c} A_{c}}\right|_{\text {Copper }}+\left.\frac{L_{d}}{k_{d} A_{d}}\right|_{\text {Droplet }}+\left.\frac{1}{h A_{d}}\right|_{\text {Air }}\right)
$$

To estimate the convective heat transfer coefficient of air, we calculate the Rayleigh number of air around the droplet, as defined below ${ }^{2}$ :

$$
R a_{\text {Droplet }}=G r_{\text {Droplet }} \cdot P r_{\text {Air }}=\frac{g \beta_{\text {Air }}\left(T_{\text {Droplet }}-T_{\text {Air }}\right) D_{\text {Droplet }}^{3}}{\gamma_{\text {Air }}^{2}} \cdot P r_{\text {Air }}
$$

where $G r_{\text {Droplet }}$ is the Grashof number of droplet, describing the ratio of buoyancy forces to viscous forces acting on the air, $g$ is the gravitational acceleration, $D_{\text {droplet }}$ is the diameter of liquid metal droplet $\beta_{\text {Air }}$ is the thermal expansion coefficient of air, $\gamma_{\text {Air }}$ is the kinematic viscosity of air, and $\operatorname{Pr}_{\text {air }}$ is the Prandtl number of air.

Consequently, the average convective heat transfer coefficient of air over the surface of droplet can be estimated as below ${ }^{2}$ :

$$
\begin{aligned}
& N u_{\text {Air }}=\frac{h_{\text {Air }} D_{\text {Droplet }}}{k_{\text {Air }}}=2+\frac{0.589 \text { Ra Droplet }}{0.25} \\
& \rightarrow h_{\text {Air }}=\left(2+\frac{0.589 R a_{\text {Droplet }}^{0.25}}{\left[1+\left(0.469 / \text { Pr }_{\text {Air }}\right)^{\frac{9}{16}}\right]^{\frac{4}{9}}}\right) \cdot \frac{k_{\text {Air }}}{D_{\text {Droplet }}}
\end{aligned}
$$

Combining equations S7 to S9, the variations of the natural convection coefficient of air with respect to the diameter of liquid metal droplet can be expressed as below:

$$
R a_{\text {Droplet }} \propto D_{\text {Droplet }}^{3} \rightarrow N u_{\text {Air }} \propto D_{\text {Droplet }}^{0.75} \rightarrow h_{\text {Air }} \propto D_{\text {Droplet }}^{-0.25}
$$

Combining equations $\mathrm{S} 7$ and $\mathrm{S} 10$, the variations of $T_{\text {hot spot }}-T_{A i r}$ with respect to the diameter of liquid metal droplet can be expressed as below: 


$$
\begin{aligned}
& \left.\frac{L_{d}}{k_{d} A_{d}}\right|_{\text {Droplet }} \propto \frac{D_{\text {Droplet }}}{D_{\text {Droplet }}^{2}} \propto D_{\text {Droplet }}^{-1} \\
& \left.\frac{1}{h A_{d}}\right|_{\text {Air }} \propto \frac{1}{D_{\text {Droplet }}^{-0.25} \cdot D_{\text {Droplet }}^{2}} \propto D_{\text {Droplet }}^{-1.75}
\end{aligned}
$$


Supporting Information 6: Variations of hot spot temperature with respect to the location of liquid metal droplet

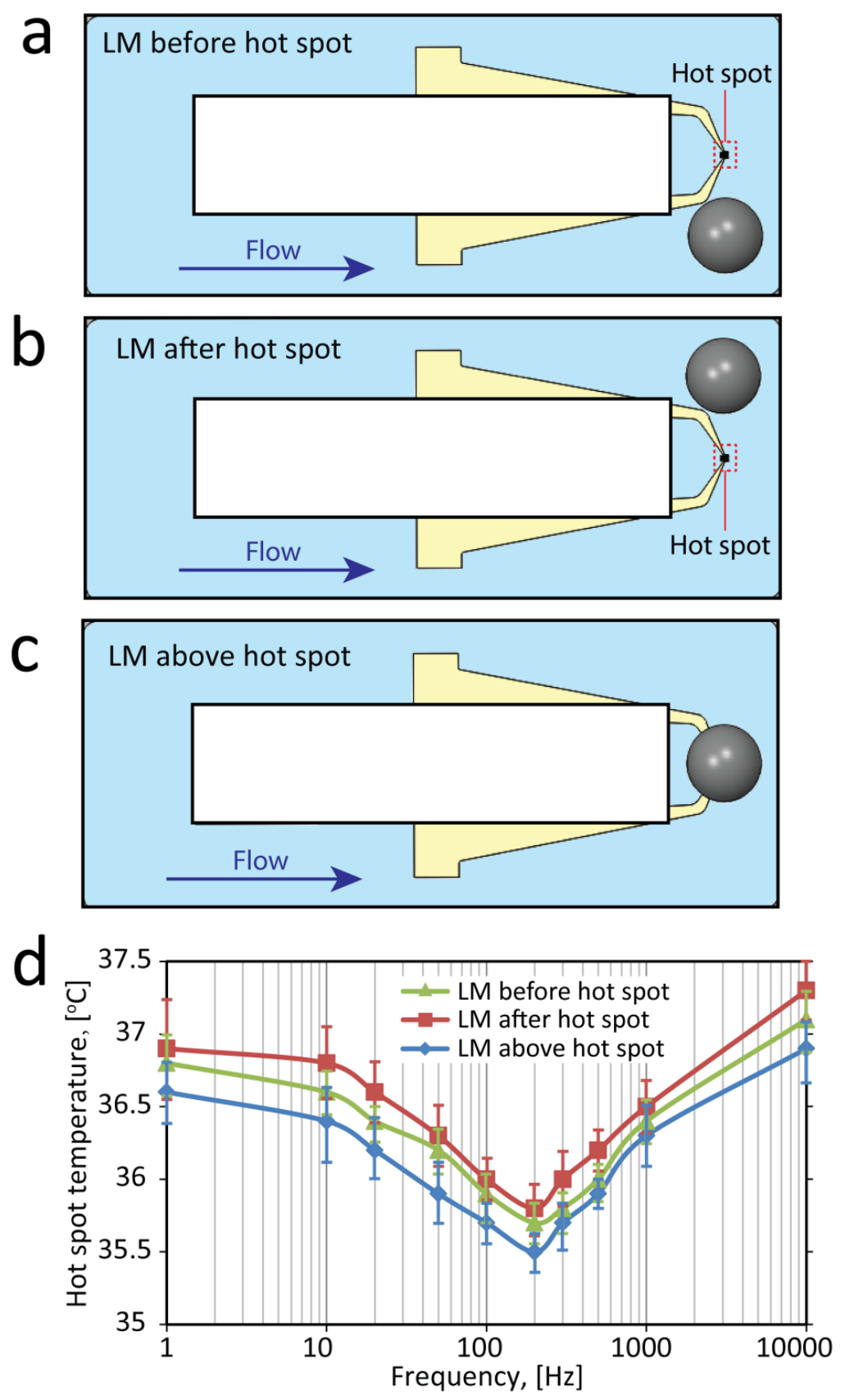

Figure S5: Hot spot temperature measured by thermistor for different operating conditions of the liquid metal based cooling system. (a-c) Schematics of liquid metal droplet at different locations with respect to hot spot. (d) Hot spot temperature measured by thermistor $v s$ droplet operating frequency when actuating droplet with a square wave signal $\left(5 \mathrm{~V}_{\mathrm{p}-\mathrm{p}}, 2.5 \mathrm{~V} \mathrm{DC}\right.$ offset and 50\% duty cycle) at different operating conditions. 
In the case of liquid metal droplet being relocated before or after the hot spot, the temperature difference between the hot spot and the surrounding $\mathrm{NaOH}$ flow is described as below:

$$
T_{\text {Hot spot }}-T_{\mathrm{NaOH}}=q\left(\left.\frac{L_{g}}{k_{g} \cdot A_{g}}\right|_{\text {Glass }}+\left.\frac{1}{h \cdot A_{C}}\right|_{\mathrm{NaOH}}\right)
$$

The maximum Reynolds number of $\mathrm{NaOH}$ flow through the cooling channel is obtained as $R e_{\text {Channel }} \sim 110$, confirming the laminar characteristics of flow while the Prandtl number of $\mathrm{NaOH}$ flow is $\mathrm{Pr}_{\mathrm{NaOH}} \sim 4.62$. Under these conditions, the convective heat transfer coefficient of $\mathrm{NaOH}$ flow over the hot spot is defined as below ${ }^{2}$ :

$$
\begin{gathered}
N u_{\mathrm{NaOH}}=\frac{h_{\mathrm{NaOH}} D_{\text {Channel }}}{k_{\mathrm{NaOH}}}=0.664 \operatorname{Re}_{\text {Channel }}^{0.5} \operatorname{Pr}_{\mathrm{NaOH}}^{0.33} \\
\rightarrow h_{\mathrm{NaOH}}=0.664 \operatorname{Re}_{\text {Channel }}^{0.5} \cdot \operatorname{Pr}_{\mathrm{NaOH}}^{0.33} \cdot \frac{k_{\mathrm{NaOH}}}{D_{\text {Channel }}}
\end{gathered}
$$

where $D_{\text {Channel }}$ is the hydraulic diameter of the cooling channel. 


\section{Supporting Information 7: Variations of hot spot temperature by adding nanoparticles}

\section{into $\mathrm{NaOH}$ solution}

Carbon black nanofluid is made by adding $5 \mathrm{mg}$ of carbon black powder (50 nm, SigmaAldrich) with a thermal conductivity of $6 \sim 174 \mathrm{~W} / \mathrm{mK}^{3}$ into $5 \mathrm{ml}$ of $0.3 \mathrm{M} \mathrm{NaOH}$ solution, providing the particle suspension with a concentration of $\sim 0.1 \mathrm{wt} \%$.

Similarly, $\mathrm{Al}_{2} \mathrm{O}_{3}$ nanofluid is made by adding $5 \mathrm{mg}$ of $5 \mathrm{mg}$ of $\mathrm{Al}_{2} \mathrm{O}_{3}$ nanoparticle powder $\left(10 \sim 50 \mathrm{~nm}\right.$, Sigma-Aldrich) with a thermal conductivity of $20 \sim 29 \mathrm{~W} / \mathrm{mK}^{3}$ into $5 \mathrm{ml}$ of 0.3 $\mathrm{M} \mathrm{NaOH}$ solution, providing the particle suspension with a concentration of $\sim 0.1 \mathrm{wt} \%$. Next, $10 \mu \mathrm{l}$ SDS (Sodium dodecyl sulfate) surfactant is added into the particle suspension and sonicated for at least $10 \mathrm{~min}$ using a high power ultrasonicator (Qsonica Sonicators) to avoid particle aggregation.
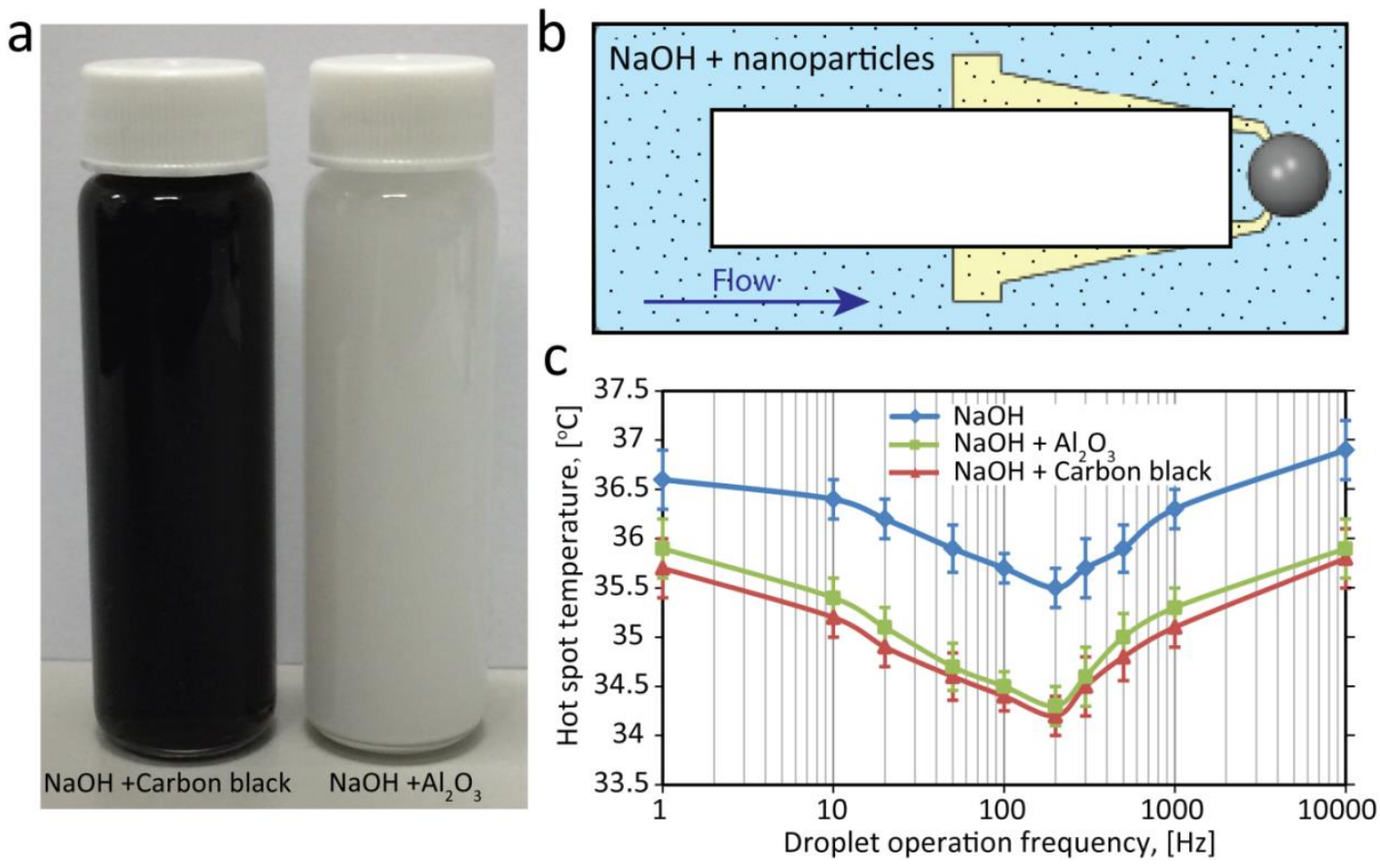

Figure S6: Hot spot temperature measured by thermistor for different operating liquid of the liquid metal based cooling system. (a) Carbon black and $\mathrm{Al}_{2} \mathrm{O}_{3}$ nanofluids. (b) Schematics of liquid metal based cooling system by circulating nanofluids. (c) Hot spot temperature measured by thermistor $v s$ different operating liquid when actuating droplet with a square wave signal (5 $\mathrm{V}_{\mathrm{p}-\mathrm{p}}, 2.5 \mathrm{~V}$ DC offset and $50 \%$ duty cycle) at different frequencies. 


\section{References:}

(1) Zhang, W.; Ou, J. Z.; Tang, S. Y.; Sivan, V.; Yao, D. D.; Latham, K.; Khoshmanesh, K.; Mitchell, A.; O'Mullane, A. P.; Kalantar-zadeh, K., Liquid metal/metal oxide frameworks. Adv. Func. Mater. 2014, 24, 3799-3807.

(2) Bergman, T. L.; Incropera, F. P.; Lavine, A. S., Fundamentals of Heat and Mass Transfer. John Wiley \& Sons: 2011.

(3) Ebadi-Dehaghani, H.; Nazempour, M., Thermal conductivity of nanoparticles filled polymers. INTECH Open Access Publisher: 2012. 